\title{
THE CHARACTERISTICS OF EXTREME MAXIMUM RUNOFF OF THE RIVERS OF ARMENIA IN THE CONTEXT OF GLOBAL CLIMATE CHANGE
}

\author{
Trahel G. Vardanyan ${ }^{1 *}$, Natalia L. Frolova ${ }^{2}$, Hrachuhi S. Galstyan ${ }^{3}$ \\ 'Yerevan State University, Yerevan, Alex Manoogian 1, 0025, Yerevan, Armenia \\ Lomonosov Moscow State University, Leninskie Gory 1, 119991, Moscow, Russia \\ ${ }^{3}$ Neijiang Normal University, Dongtong Rd, Dongxing District, Neijiang, Sichuan, 705, China \\ *Corresponding author: tvardanian@ysu.am \\ Received: July 10 ${ }^{\text {th }}, 2020$ / Accepted: February 16 ${ }^{\text {th }}, 2021$ / Published: April 1 $1^{\text {st }}, 2021$ \\ https://DOI-10.24057/2071-9388-2020-122
}

\begin{abstract}
The study concerned the analysis of temporal and spatial variability of floods in the Republic of Armenia (RA). While there are number of reports on flood formation of rivers in RA, the literature lacks results on using nonparametric test results to analyze this disastrous phenomenon. For that purpose, the dynamics of changes in extreme maximum instantaneous runoff, as well as air temperature and precipitation database was evaluated and compared between 1960-2012 for 27 hydrometrical observational and 35 meteorological stations in RA. The Mann-Kendall test with consideration of the autocorrelation function was employed as a non-parametric testto identify any present trends. An increasing tendency of air temperature, decreasing tendency of the atmospheric precipitation and extreme maximum instantaneous river runoff were identified in the studied river-basins. As expected, the warming climate contributed to a gradual melting of accumulated snow in the river-basins in winter, resulting in changes in the extreme maximum instantaneous runoff of the rivers in spring, which significantly reduces the risk of the flood occurrence. Thus, it can be claimed that almost all the river basins of Armenia have a tendency to reduce the risk of floods due to global climate change.
\end{abstract}

KEY WORDS: maximum runoff, climate change, precipitation, variability, trend, flooding risk

CITATION: Trahel G. Vardanyan, Natalia L. Frolova, Hrachuhi S. Galstyan (2021). The Characteristics Of Extreme Maximum Runoff Of The Rivers Of Armenia In The Context Of Global Climate Change. Geography, Environment, Sustainability, Vol.14, No 1, p. 196-208 https://DOl-10.24057/2071-9388-2020-122

Conflict of interests: The authors reported no potential conflict of interest.

\section{INTRODUCTION}

The $20^{\text {th }}$ century was marked by global changes in the social, political, and economic spheres that impacted the state of the environment, including water bodies. These changes in environmental components have been associated with the increase of greenhouse gas concentration in the atmosphere and the growth of temperature of the sub-surface layer of the atmosphere (Solomon et al. 2007).

Studies showed that from 1929 to 2015 the average annual air temperature increased by 1,030C and precipitation decreased by $10 \%$ in Armenia (Armenia's Third National Communication on Climate Change 2015) compared with the baseline period from 1961 to 1990 (adopted by the Intergovernmental Expert Group on Climate Change department).

The negative impact of global climate change on the Earth is evident everywhere, including the RA. It is particularly expressed by the increasing vulnerability of ecosystems, frequent natural disasters, observed extreme climate and hydrologic values, desertification, droughts, and other phenomena and risks (Anthony J. et al. 2009; Zaqaryan et al. 2018). It is challenging to find a sphere unaffected by climate change.

The geographical location of the Republic of Armenia, the variety of relief, the compound geological structure
(Physical geography of the Armenian USR 1971; Geology of the Armenian USR 1974), the presence of a seismic zone, and the collisions of various atmospheric fronts create suitable conditions for the occurrence of natural disasters, in particular, for floods formation (Vardanian 2008). Those disasters are becoming more frequent and often result in substantial economic damage and numerous casualties. For example, the financial losses caused by natural disasters in the South Caucasus over the past two decades have exceeded \$16 billion (Atlas of Natural Hazards and Risk in Georgia 2012).

Floods have been the most frequent disasters, being much more dangerous than any other natural disaster in the world, as the flood covers significant areas of land, causing numerous human victims and enormous material damage (Transboundary Floods 2005; Anthony J. et al. 2009). Floods formed in the river basins are one of the most common types of floods. Floods are especially dangerous for mountainous regions, because most of the river basins are located in residential areas. Floods causing significant material losses, destruction, human victims, mud runoffs and landslides are frequent and very common in the Republic of Armenia (Vardanyan 2005; Vardanyan 2009). However, unlike other natural disasters, floods are somewhat predictable.

While there are various scientific reports concerning river flood formation in RA (Vardanyan 2005; Vardanian 2007; Anthony J. et al. 2009), little consideration was paid to 
using nonparametric test results to analyze this disastrous phenomenon. Therefore, the objectives of the present study are (1) to explore and evaluate the characteristics of the flood formation in RA rivers, (2) to analyze their changes in the 19602012 period with respect to precipitation and air temperature changes at the same river basins and (3) to identify the impact of climate change on observed extreme maximum instantaneous runoffs of the river basins.

\section{RESEARCH AREA, MATERIAL AND METHODS}

\section{Research Area}

The Republic of Armenia is located in the northeast of the Armenian Highlands. In the north, Armenia borders Georgia, in the east - Azerbaijan, in the west and southwest - Turkey, and in the south - Iran. The territory of RA is $29743 \mathrm{~km}^{2}$. RA is a mountainous country: $76.5 \%$ of the territory has altitudes of 1000-2500 meters above the sea level (a.s.l.) (Fig. 1), with an average elevation of $1800 \mathrm{~m}$ a. s. I. and with extremes ranging from 380 m a. s. I. (Debed River-bed) to 4090 m a. s. I. (summit of Aragats Mt).

Armenia is a country of climate contrasts. Due to a complicated topography and microclimatic particularities, significant climate diversity is observed through neighboring small watersheds. Almost all climatic types starting from arid subtropical to cold high mountainous can be found in Armenia (Nersisyan 1964).

The average annual air temperature is $5.5^{\circ} \mathrm{C}$ (it is below zero in altitudes above $2500 \mathrm{~m}$ ), and the highest average annual temperature is $12-14^{\circ} \mathrm{C}$. The summer is temperate: the average temperature at the end of July is $16.7^{\circ} \mathrm{C}$, while in Ararat valley it ranges between $24-26^{\circ} \mathrm{C}$. The recorded absolute maximum temperature is $43.7^{\circ} \mathrm{C}$ (Scientific Applied Directory on the USSR Climate 1989). Winters are cold, January being the coldest winter month, with an average temperature of $-6.7^{\circ} \mathrm{C}$ and a recorded absolute lowest temperature of $-42^{\circ} \mathrm{C}$. Winters in the northeastern and southeastern parts of the country are temperate.

The average annual precipitation in RA amounts to 592 $\mathrm{mm}$, where the Ararat Valley and Meghri region are the aridest zones, with annual precipitation of around 200-250 mm and with average summer precipitation of around $32-36 \mathrm{~mm}$ in the Ararat valley. The highest precipitation is observed in high mountainous areas: about $1000 \mathrm{~mm}$ per year.

The average annual wind speed in RA is unevenly distributed, in the range of 1.0-8.0 m/sec. Mountain winds are quite common for some regions, particularly for Ararat valley. During the summer months, their velocity reaches and exceeds $20 \mathrm{~m} / \mathrm{sec}$ (Armenia's Third National Communication on Climate Change 2015).

In RA, the rivers belong to the Araks (76.4\% of the territory) and the Kur (23.6\%) river basins (Fig. 1). These are 380 rivers with a cumulative length of over $10 \mathrm{~km}$ in the country (The Hydrography of Armenian SSR 1981).

The hydrometric and hydrological features of the relatively large rivers of the Republic of Armenia are shown in Table 1.

\section{Material}

Meteorological and hydrological data taken from Armstatehydromet official observations (Climate Bulletin of the Republic of Armenia 2011), existing scientific sources, as well as climatic and hydrological atlases are used for the implementation of this article (Atlas of the natural conditions of the natural resources of the Republic of Armenia, Hydrology 1990).

The dynamics of changes in the extreme maximum instantaneous runoff of the rivers, air temperature, and atmospheric precipitation data are compared and evaluated

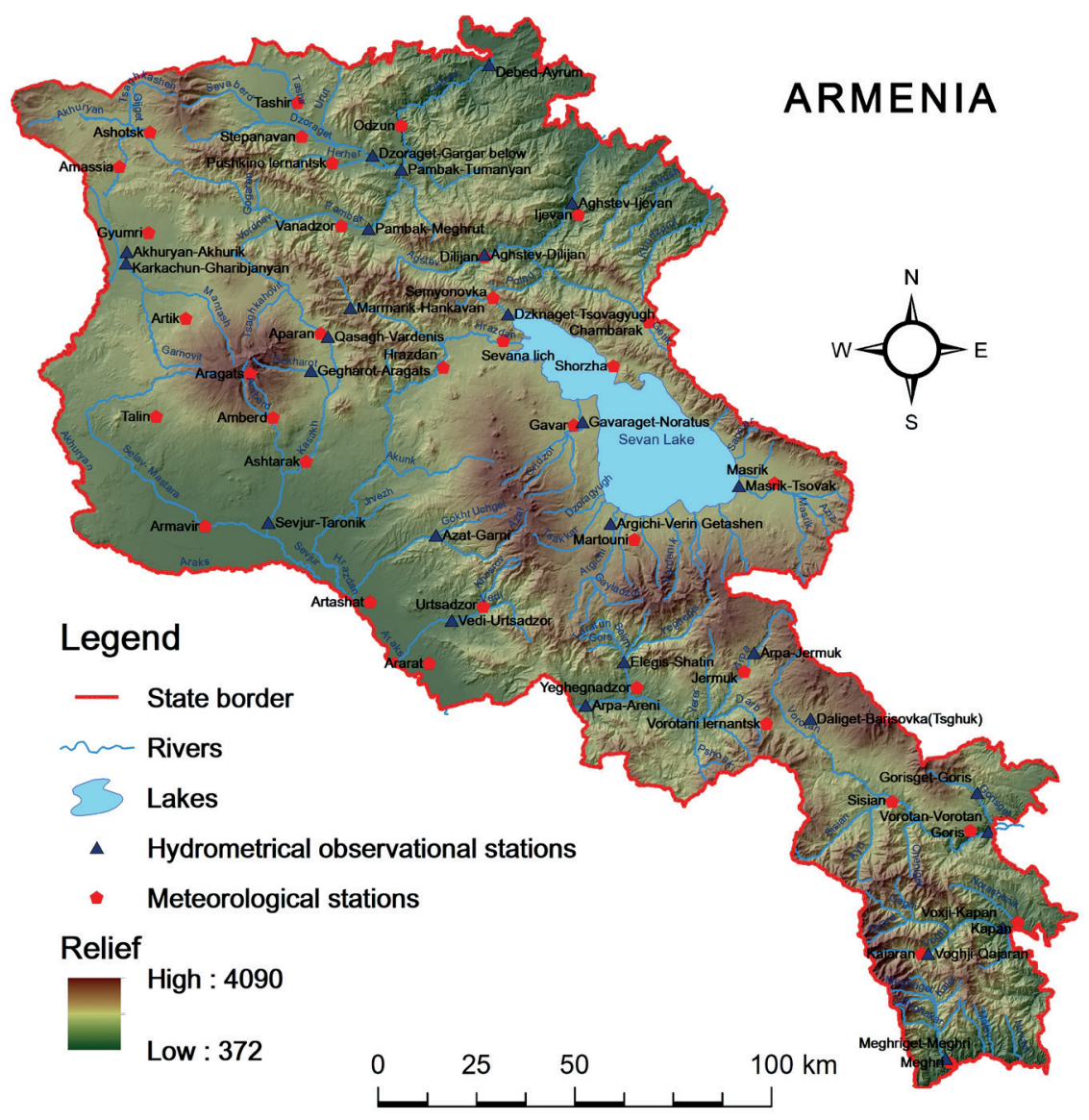

Fig. 1. Geographic distribution of the hydrometrical and meteorological observational stations used in the study 
Table 1. The hydrometric and hydrological features of the relatively large rivers of the Republic of Armenia (according to Armstatehydromet data)

\begin{tabular}{|c|c|c|c|c|c|c|}
\hline \multirow{2}{*}{$\mathrm{N}$} & \multirow{2}{*}{ River - Hydrometric station } & \multirow{2}{*}{$\begin{array}{l}\text { Catchment area, } \\
\mathrm{km}^{2}\end{array}$} & \multirow{2}{*}{$\begin{array}{l}\text { The average } \\
\text { height of the } \\
\text { catchment area, } \\
\text { m }\end{array}$} & \multirow{2}{*}{$\begin{array}{c}\text { The average } \\
\text { annual runoff } \\
\text { of river water, } \\
\mathrm{m}^{3} / \mathrm{s}\end{array}$} & \multicolumn{2}{|c|}{$\begin{array}{l}\text { Extreme maximum instantaneous } \\
\text { runoff }\end{array}$} \\
\hline & & & & & $\mathrm{m}^{3} / \mathrm{s}$ & Monitoring time \\
\hline 1 & Debed - Ayrum & 3740 & 1770 & 33.2 & 759 & 19.05.1959 \\
\hline 2 & Dzoraget - Gargar & 1450 & 1860 & 15.4 & 395 & 19.051959 \\
\hline 3 & Pambak - Meghrut & 1070 & & 7.89 & 109 & 14.06.1963 \\
\hline 4 & Pambak - Tumanyan & 1370 & 1920 & 10.4 & 171 & 23.06.1976 \\
\hline 5 & Aghstev - Dilijan & 303 & 2000 & 3.11 & 53.1 & 31.05.1978 \\
\hline 6 & Aghstev - ljevan & 1270 & 1800 & 9.54 & 177 & 1990 \\
\hline 7 & Akhuryan - Akhurik & 1060 & 2100 & 9.93 & 182 & 18.04 .1968 \\
\hline 8 & Karkachun - Gharibjanyan & 1020 & 2020 & 1.04 & 79.4 & 27.03.1964 \\
\hline 9 & Qasakh - Vardenis & 441 & 2300 & 1.26 & 151 & 12.04 .1972 \\
\hline 10 & Gegharot - Aragats & 40 & 3100 & 0.96 & 18.7 & 19.07.1933 \\
\hline 11 & Sevjur - Taronik & 1560 & 1410 & 14.37 & 43.6 & 06.05.1966 \\
\hline 12 & Marmarik - Hankavan & 94 & 2430 & 1.65 & 31.3 & 26.04.1960 \\
\hline 13 & Dzknaget - Tsovagyugh & 85 & 2220 & 1.1 & 28.1 & 06.05 .2007 \\
\hline 14 & Gavaraget - Noradus & 467 & 2430 & 3.8 & 49 & 03.07.1997 \\
\hline 15 & Argichi - Verin Getashen & 384 & 2470 & 5.6 & 171 & 17.04.1968 \\
\hline 16 & Masrik - Tsovak & 685 & 2310 & 4.1 & 20.3 & 30.04 .1969 \\
\hline 17 & Azat - Garni & 326 & 2420 & 4.8 & 83.9 & 09.05.1963 \\
\hline 18 & Vedi - Urtsadzor & 329 & 2090 & 1.9 & 53.8 & 11.09 .1974 \\
\hline 19 & Arpa - Jermuk & 180 & 2790 & 5.3 & 91 & 17.05.1983 \\
\hline 20 & Arpa - Areni & 2040 & 2110 & 16.9 & 340 & 01.04 .1969 \\
\hline 21 & Elegis - Shatin & 458 & 2350 & 6.95 & 207 & 30.06 .1997 \\
\hline 22 & Daliget - Borisovka & 136 & 2780 & 1.37 & 46.6 & 14.05.1967 \\
\hline 23 & Vorotan - Vorotan & 2020 & 2280 & 22.6 & 300 & 18.04.1968 \\
\hline 24 & Gorisget - Goris & 85 & 2180 & 0.95 & 46.4 & 18.06.1967 \\
\hline 25 & Voghji - Kajaran & 120 & 2840 & 3.27 & 43.9 & $04,05,21,24.07 .1960$ \\
\hline 26 & Voghji - Kapan & 685 & 2380 & 11.1 & 133 & $15,16.05(2) 2010$ \\
\hline 27 & Meghriget - Meghri & 274 & 2200 & 3.5 & 87.5 & 12.04 .1956 \\
\hline
\end{tabular}

for 27 hydrometrical observational and 35 meteorological stations in RA (for the 1960-2012 period). The selected stations' geographic description is given in Fig. 1. The meteorological stations supervised by the Armenian Hydrometeorological center were selected to cover all climatic zones in the country. These locations were chosen according to the following parameters: the data should be reliable, each of them should have acceptable quality datasets, and the data should have adequate record length. In addition to relatively long duration of observation, river observation points with existing meteorological stations were selected. The database consisted of the maximum instantaneous river runoff, average annual air temperatures and atmospheric precipitation for each station in each calendar year.

The rivers were selected based on the principle of having different physical-geographical conditions (Fig. 1): In particular, the different elevations of the relief (average altitudes of the catchment basins range from 2090 to $3100 \mathrm{~m}$ ), different geological conditions (volcanic and constricted mountains), various types of climate (the lower parts of the selected rivers have arid subtropical climate, while the upper parts have cold high mountainous climate (Nersisyan 1964)). The stations are located within the catchments (Fig. 1 and Table 1), and their areas range from $40 \mathrm{~km}^{2}$ (Gegharot - Aragats) to $3740 \mathrm{~km}^{2}$ (Debed Ayrum).

The elaborated study period (1960-2012) was chosen based on the data availability in terms of record duration and spatial coverage. In addition, results of the current research were compared with similar results obtained elsewhere for European rivers (Blösch G. et al. 2019). The dataset was screened for data errors, and catchments that were known or were identified to have strong human influence (such as reservoirs) on the flood discharges were excluded (for instance, one of the largest rivers in the central part of Armenia was Hrazdan river basin with an area of $2310 \mathrm{~km}^{2}$ ).

\section{Methods}

This study's methodological approach consists of the following logical steps: the temporal statistical analysis, the spatial statistical analysis, and the identification of extreme maximum instantaneous runoff of the rivers in RA (Fig. 1). 
Thus, the main objective of the study is the determination of some hydrometeorological characteristics in Armenia using nonparametric Mann-Kendall (MK) test. This trend analysis is typical in environmental sciences (Mann 1945). The MK test results were obtained using the «Kendall» package in R Studio 3.7 programming language.

MK test is a statistical test widely used to analyze trends in climatologic and hydrologic time series (Yue and Wang 2004). There are two advantages of using this test: First, it is a nonparametric test and does not require the data to be normally distributed. Second, the test has low sensitivity to abrupt breaks due to inhomogeneous time series (Stephens and Ellis 2008). Any data reported as nondetects are included by assigning them a common value that is smaller than the smallest measured value in the data set (Kendall 1975). According to this test, the rejection of the null hypothesis $\mathrm{H}_{0}$ assumes that there is a trend in the time series, while accepting $\mathrm{H}_{0}$ indicates no trend detected, and the result is said to be statistically significant.

In order to remove serial correlation from the series, it was suggested pre-whitening the series before applying MK test (Von Storch and Navarra 1995). The critical value of the lag-1 serial correlation coefficient $\left(r_{1}\right)$ for a given significance level depends on whether the test is onetailed or two-tailed (a one-tailed test is used in the current report). The probability limits on the correlogram of an independent series for $r$ can be computed by (Anderson 1942; Salas et al. 1980),

$$
r=\frac{-1+1.645 \sqrt{n-2}}{n-1} \text { (one tailed-test) }
$$

It helps to find out the autocorrelation inside the series and to detect a possible trend. The values must be between -1 and +1 . There is a positive correlation if the result is near +1 , and there is a negative correlation if it is close to -1 . In MK test, if the autocorrelation is $r \geq \pm 0,22718$, then the members of the series must be recalculated in the following way (Mann 1945),

$$
\left(x_{2}-r x_{1}, x_{3}-r x_{2} \ldots x_{n}-r x_{n-1}\right)
$$

The resultant Mann-Kendall test statistic (S) indicates how strong the temperature trend is and whether it is increasing or decreasing (the sign of $\mathrm{S}$ indicates the slope of the trend).

$$
S=\sum_{i=1}^{n-1} \sum_{j=i+1}^{n} \operatorname{sign}\left(T_{j}-T_{i}\right)
$$

where $T$ and $T$ are the annual temperature, precipitation and flood values in years $j$ and $i, j>i$, respectively, (Jones and Wigley 1986; Kendall 1975) indicates how strong the trend in precipitation is and whether it is increasing or decreasing.

Another statistic obtained on running the MK test is Kendall's tau,

$$
\tau=\frac{S}{D}
$$

where $D$ is the maximum possible value of $S$. Kendall's tau is a measure of correlation and therefore measures the strength of the relationship between the two variables. Kendall's tau is carried out on the ranks of the data (Kendall 1975).

In the case of no relations between two $-X$ and $Y$ series

$$
D=\left(\frac{n}{2}\right)
$$

The $S$ parameter shows the possible trend, and the sign (mins or plus) indicates if the trend is negative or positive.
In general, if there are $n_{x}$ relations with the size of $t_{i}$, where $i=1, \ldots, n_{x}$ inside $X$ series, $n_{y}$ relations with the size of $t_{j}$, where $j=1, \ldots, n_{y}$ inside $Y$, then

$$
D=\sqrt{\left(\left(\frac{n}{2}\right)-T\right)\left(\left(\frac{n}{2}\right)-U\right)}
$$

where

$$
T=\frac{1}{2} \sum_{i=1}^{n_{x}} t_{i}\left(t_{i}-1\right) ; U=\frac{1}{2} \sum_{j=1}^{n_{y}} u_{j}\left(u_{j}-1\right)
$$

For the time series analysis, it is essential to consider autocorrelation or serial correlation, defined as the correlation of a variable with itself over successive time intervals, prior to testing for trends. Autocorrelation increases the chances of detecting significant trends even if they are absent and vice versa. In order to consider the effect of autocorrelation, a modified MK test applied, which calculates the autocorrelation between the ranks of the data after removing the apparent trend (Khaled at. el. 1998). The adjusted variance is given by:

$$
\begin{gathered}
\operatorname{Var}(S)=\frac{1}{18} n(n-1)(2 n+5)-\frac{n}{n S^{*}} \\
\frac{n}{n S^{*}}=1+\frac{2}{n(n-1)(n-2)} \sum_{i=1}^{\rho}(n-1)(n-i-1)(n-i-2) p_{s}(i)
\end{gathered}
$$

$n$ is the number of observations in the sample, $n S^{*}$ is the effective number of observations to account for autocorrelation in the data $p_{s}(i)$, is the autocorrelation between ranks of the observations for lag- 1 , and $p$ is the maximum time lag under consideration.

$$
P \leq 0.05
$$

Significance is set at the 95\% level ( $a=0.05$ ). If the $p$-value is less than the significance level a (alpha), the hypothesis $H_{0}$ is rejected. Rejecting $H_{0}$ indicates a trend in the time series, while accepting $H_{0}$ indicates no trend detected and the result is said to be statistically significant.

For $Z$ series having $n$ observations data, where $t=1, \ldots, n$, Mann suggested using Kendall's rank correlation for checking monotone changes (Mann 1945). The acceptance of the null hypothesis $H_{0}$ assumes that in $Z$ series, where $t=1, \ldots, n$, members are distributed independently:

$$
\begin{aligned}
& Z=\frac{S-1}{[\operatorname{VAR}(S)]^{\frac{1}{2}}} \text { if } S>0 \\
& Z=0 \text { if } S=0 \\
& Z=\frac{S+1}{[\operatorname{VAR}(S)]^{\frac{1}{2}}} \text { if } S<0
\end{aligned}
$$

Thus, it could be said that the applied method in the article allowed to study the trend in the series and to find out some regularities in them.

Moreover, the Mann-Kendall test for trend analysis, besides the 'S' Statistic, relies on another two statistical metrics (Aziz et al. 2003):

$\sqrt{ }$ The Confidence Factor (CF): The CF value modifies the $S$ Statistic calculation to indicate the degree of confidence in the trend result, as in 'Decreasing» vs. "Probably Decreasing» or «Increasing» vs. "Probably Increasing.» Additionally, if the confidence factor is quite low, either due to considerable variability in concentrations vs. time or little change in concentrations vs. time, the CF is used to apply a preliminary «No Trend» classification, pending consideration of the COV. $\sqrt{ }$ The Coefficient of Variation (COV): The COV is used to distinguish between a «No Trend» result (significant scatter in concentration trend vs. time) and a «Stable» result (limited variability in concentration vs. time) for datasets with no significant increasing or decreasing trend (e.g. low CF). 
Technically, the CF is the measure of confidence for rejecting the null hypothesis of «No trend» vs. time. The null hypothesis $\left(H_{0}\right)$ states that the dataset shows no distinct linear trend over time. The probability ( $p$ ) of accepting $H_{0}$ is determined from the MK table of probabilities (included in the software), which are based on the number of sample events $n$, and the extreme value of $\mathrm{S}$. Specifically, $p$ is the probability of obtaining a value of $S$ equal to or greater than the calculated value for $n$ events when no trend is present. In MK test, $H_{0}$ is rejected when $\mathrm{p}<$ 0.1 (corresponding to $a=0,1$, i.e. below a $90 \%$ CF). Here the $C F$ is $(1-p) \%$. The CF is inversely proportional to $p$ (higher for lower $p$ values) and directly proportional to both $S$ and $n$ (higher CF for higher $S$ and higher $n)$. When CF $>95 \%(p<0.05)$, the data demonstrate a strong, either «Increasing» or «Decreasing» trends. When the CF falls between 90 to $95 \%(0.1>p>0.05)$, the $\mathrm{H}_{0}$ is rejected, and a trend is indicated; however, due to the lower confidence in the trend, the qualifier «Probably» is applied, as in «Probably Increasing» or «Probably Decreasing.» If the CF is less than $90 \%(p>0.1)$, the $H_{0}$ is accepted and either a «No Trend» condition or a «Stable» condition is indicated, depending on the COV, as described below.

Depending on the values of the S Statistic and the COV, sampling locations that exhibit a low CF $(C F<90 \%)$ are designated as either'Stable' $(S \leq 0$ and COV $<1$ ) or'No Trend' (COV z 1) (Table 2).

\section{RESULTS AND DISCUSSION}

The trend analysis of temperature series changes

The long-term measurements and observations of air temperature and atmospheric precipitation data taken from the national meteorological services of Armenia were sourced from the chosen 35 meteorological stations located in the studied river basins and were distributed across the whole country (Fig. 1). The average annual air temperature data, atmospheric precipitation and extreme maximum instantaneous river runoff taken from the measuring period of 1960-2012 were used in the study. The presence of trends in annual temperature was assessed by means of MK test and autocorrelation function, a nonparametric test searching for the presence of some trends in the longtime evolution of air temperature, atmospheric precipitation, and extreme maximum instantaneous river runoff.

According to MK test requirements, we have to get autocorrelation results (lag-1 serial correlation) for the data series before applying the data. As it was already mentioned, if the autocorrelation coefficient was $\geq| \pm 0.22718|$, then the data series needed to be recalculated, according to Mann test (1945). The analysis was obtained by MK after eliminating the effect of significant lag-1 serial correlation from the time series. Lag-1 was not significant at the $5 \%$ level in 10 series out of 35 , therefore they were pre-whitened before using in MK test (the others were applied to the original values of the time series).

Autocorrelation plots for the meteorological variables at the ten weather stations are presented in Fig. 2.1.

As shown in Fig. 2, only positive serial correlations were obtained for temperature. The strongest serial correlations were found at Kapan and Urtsadzor stations (below 1000m a. s. I.).

After pre-whitening, according to this test, we had the following results. The Null Hypothesis $(\mathrm{HO})$ was accepted for 14 stations (meaning that no trend is found for these stations), while for 21 remaining stations, it was rejected (there are trends), as shown in Table 3. According to these results, no air temperature decrease was observed in Armenia during the studied periodwhich is an indication of air temperature raise.

There was no trend detected for the remaining 14 stations. According to the test requirements, the confidence of positive or negative changes in the data series were explained by «p-value».

Table 2. Statistical Metrics Used in the Mann-Kendall test (Aziz et al. 2003)

\begin{tabular}{|c|c|c|}
\hline S Statistic & Confidence in Trend & Trend \\
\hline $\mathrm{S}>0$ & $\mathrm{CF}>95 \%$ & Increasing \\
\hline $\mathrm{S}>0$ & $95 \% \geq \mathrm{CF} \geq 90 \%$ & Probably Increasing \\
\hline $\mathrm{S}>0$ & $\mathrm{CF}<90 \%$ & No Trend \\
\hline $\mathrm{S} \leq 0$ & $\mathrm{CF}<90 \%$ and $\mathrm{COV} \geq 1$ & No Trend \\
\hline $\mathrm{S} \leq 0$ & $\mathrm{CF}<90 \%$ and $\mathrm{COV}<1$ & Stable \\
\hline $\mathrm{S}<0$ & $95 \% \geq \mathrm{CF} \geq 90 \%$ & Probably Decreasing \\
\hline $\mathrm{S}<0$ & $\mathrm{CF}>95 \%$ & Decreasing \\
\hline
\end{tabular}
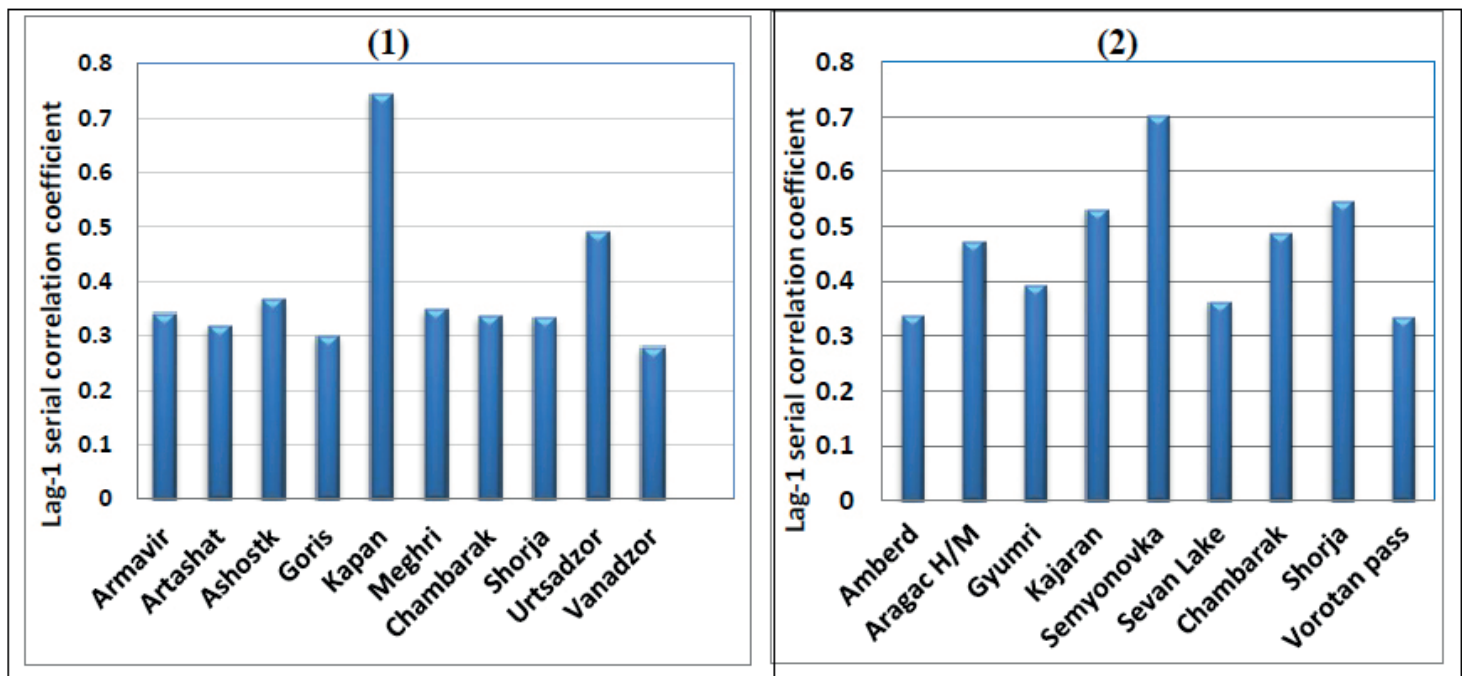

Fig. 2. Lag-1 serial correlation coefficient for the meteorological variables at the weather stations for annual average temperature (1) and atmospheric precipitation (2) 
The spatial distribution of weather stations with increasing and no trends for the annual data series during the 1960-2012 period is presented in Fig. 3. As shown, the significant increasing trends in annual temperature were detected at 21 of the observed stations. The strongest significant increasing trend was found for
Yeghegnadzor $(p=0.001765, T=0.343236)$ and Artashat ( $p=0.0036364, T=0.28966)$ stations.

Applying MK test and getting results for every station, the schematic map can be created (Fig. 3), where it is possible to notice the detected «lncreasing» or «No trend» stations.

Table 3. The «Rejected $\mathrm{H}_{0}$ " test results for annual average air temperature over the period 1960-2012

\begin{tabular}{|c|c|c|c|c|c|c|}
\hline Name of stations & $\begin{array}{l}Z \text { (variation } \\
\text { value of S) }\end{array}$ & $\begin{array}{l}P \text { (maximum } \\
\text { value of lag) }\end{array}$ & $\begin{array}{l}\text { S (Kandell } \\
\text { coefficient) }\end{array}$ & Tau T(S/D) & $\begin{array}{l}\mathrm{D} \text { (maximum } \\
\text { value of } \mathrm{S} \text { ) }\end{array}$ & $\begin{array}{c}\text { Test } \\
\text { interpretation }\end{array}$ \\
\hline Amasia & 2.2614055 & 0.0237342 & 291.0937 & 0.2195277 & 1326 & Rejected $\mathrm{H}_{0}$ \\
\hline Aparan & 2.2600852 & 0.023816 & 249.36763 & 0.2306824 & 1081 & Rejected $\mathrm{H}_{0}$ \\
\hline Artashat & 2.9080915 & 0.0036364 & 340.6402 & 0.28966 & 1176 & Rejected $\mathrm{H}_{0}$ \\
\hline Ashostk & 1.9768297 & 0.0480609 & 246.70418 & 0.1934935 & 1275 & Rejected $\mathrm{H}_{0}$ \\
\hline Dilijan & 2.8782381 & 0.003999 & 362.20774 & 0.2840845 & 1275 & Rejected $\mathrm{H}_{0}$ \\
\hline Jermuk & 2.0134842 & 0.0440637 & 237.58239 & 0.2020258 & 1176 & Rejected $\mathrm{H}_{0}$ \\
\hline Yeghegnazor & 3.1270847 & 0.0017655 & 281.45355 & 0.343236 & 820 & Rejected $\mathrm{H}_{0}$ \\
\hline Gavar & 1.9715018 & 0.0486665 & 247.39479 & 0.1940351 & 1275 & Rejected $\mathrm{H}_{0}$ \\
\hline Goris & 2.7109032 & 0.00671 & 339.72795 & 0.2664533 & 1275 & Rejected $\mathrm{H}_{0}$ \\
\hline Gyumri & 2.3316821 & 0.0197174 & 256.5037 & 0.2372837 & 1081 & Rejected $\mathrm{H}_{0}$ \\
\hline Martuni & 2.7264622 & 0.0064017 & 340.38187 & 0.2669662 & 1275 & Rejected $\mathrm{H}_{0}$ \\
\hline Masrik & 2.0487062 & 0.0404909 & 264.12921 & 0.1991925 & 1326 & Rejected $\mathrm{H}_{0}$ \\
\hline Meghri & 2.5168019 & 0.0118425 & 315.50071 & 0.2474515 & 1275 & Rejected $\mathrm{H}_{0}$ \\
\hline Odzun & 2.1909045 & 0.0284587 & 282.48568 & 0.213036 & 1326 & Rejected $\mathrm{H}_{0}$ \\
\hline Sevan Lake & 2.626442 & 0.0086283 & 338.17727 & 0.2550357 & 1326 & Rejected $\mathrm{H}_{0}$ \\
\hline Sisian & 2.336992 & 0.0194396 & 292.79857 & 0.2296459 & 1275 & Rejected $\mathrm{H}_{0}$ \\
\hline Stepanavan & 2.2622542 & 0.0236817 & 291.77836 & 0.220044 & 1326 & Rejected $\mathrm{H}_{0}$ \\
\hline Tashir & 2.7121334 & 0.0066852 & 349.24533 & 0.2633826 & 1326 & Rejected $\mathrm{H}_{0}$ \\
\hline Urtsadzor & 2.1209145 & 0.033929 & 257.66986 & 0.2103427 & 1225 & Rejected $\mathrm{H}_{0}$ \\
\hline Vanadzor & 2.8484065 & 0.0043939 & 344.96377 & 0.2816031 & 1225 & Rejected $\mathrm{H}_{0}$ \\
\hline Vorotan pass & 2.6898287 & 0.0071489 & 325.82331 & 0.2659782 & 1225 & Rejected $\mathrm{H}_{0}$ \\
\hline
\end{tabular}

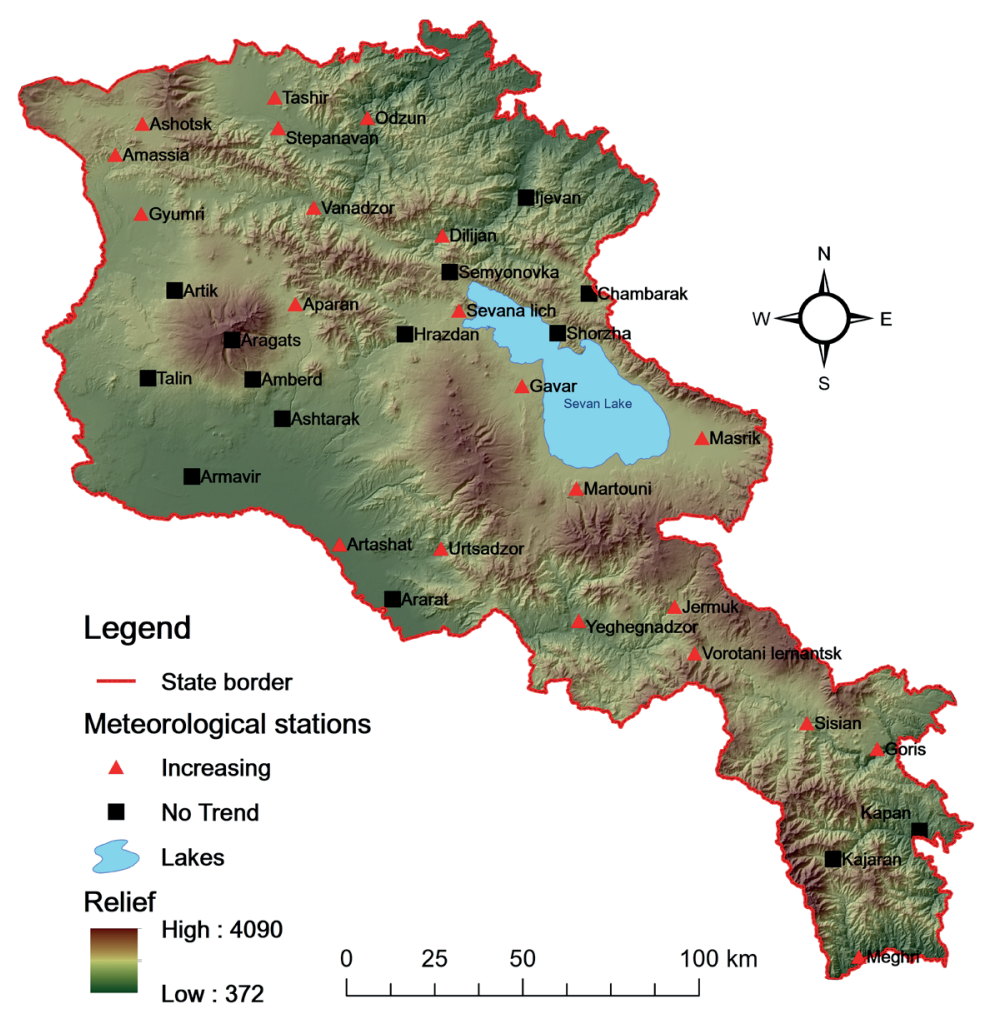

Fig. 3. Mann-Kendall test results for average annual temperature over the period 1960-2012 
As it can be seen from Fig. 3, there are twice as many stations with «Increasing» result as stations having «No trend» result. This meant that about $60 \%$ of the territory experienced temperature change, and the temperature change had exclusively positive trend (in contrast to precipitation). «No trend» was detected in the south, the west, the southeastern slopes of Aragats mountain, towards south-east from Sevan Lake, Voghji valley, the northeastern and the southeastern parts of the Ararat valley.

It has been an accepted fact that the majority of the territory of Armenia experienced temperature change since 1990's, and the results reported in this study confirm that the global climate change especially began to influence the Armenian climate during the last 2 decades.

According to the overall test results, there was a regional variability in Armenia's annual temperature as a consequence of having complicated relief conditions. Some parts of Armenia experienced a greater increase in temperature, while some parts experienced less increases or no trend.
The trend analysis of precipitation series changes

Similar to air temperature data, the atmospheric precipitation data wasanalyzed as well,the results of which are demonstrated in Fig. 4 and Table 4. In 9 out of 35 series lag-1 was not significant at the $5 \%$ level, compared to MK test. Thus we 'pre-whitened' those time series, but the others were applied to the time series's original values. Autocorrelation plots for the meteorological variables at the nine weather stations are presented in Fig. 2.

As shown in Figure 2 only positive serial correlations were obtained for precipitation, which indicates that there is a positive or direct relation inside the series. Similar results were obtained for air temperature series as well. The strongest serial correlations were found in the series of Semyonovka, Shorja and Kajaran stations.

For this test, the Null Hypothesis was accepted for 26 stations (this meant that no trend was seen for these stations), while it was rejected for nine stations (there were trends) (Table 4). It was found that the change in precipitation across

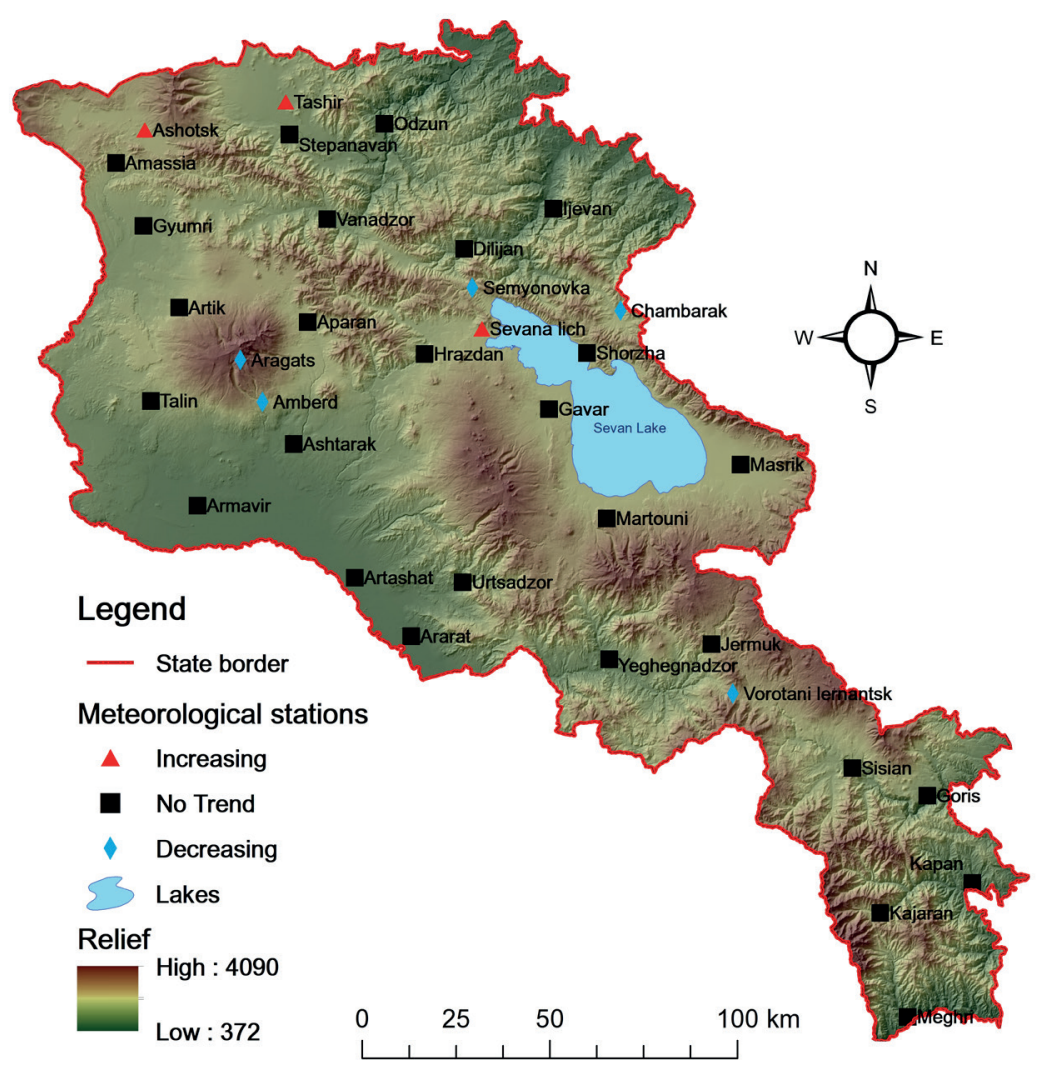

Fig. 4. Mann-Kendall test results for annual average atmospheric precipitation over the period 1960-2012

Table 4. Results of the Mann-Kendall test for annual precipitation over the period 1960-2012

\begin{tabular}{|c|c|c|c|c|c|c|c|}
\hline $\begin{array}{l}\text { Name of } \\
\text { station }\end{array}$ & $\begin{array}{c}\text { Station height, } \\
h(\mathrm{~m})\end{array}$ & $\begin{array}{l}Z \text { (variation } \\
\text { value of S) }\end{array}$ & $\begin{array}{l}P \text { (maximum } \\
\text { value of lag) }\end{array}$ & $\begin{array}{l}\text { S (Kandell } \\
\text { coefficient) }\end{array}$ & Tau T(S/D) & $\begin{array}{l}\mathrm{D} \text { (maximum } \\
\text { value of } \mathrm{S} \text { ) }\end{array}$ & $\begin{array}{c}\text { Test } \\
\text { interpretation }\end{array}$ \\
\hline Amberd & 2071 & -3.273 & 0.001 & -403 & -0.316 & 1275 & Rejected $\mathrm{H}_{0}$ \\
\hline Aragats h/m & 3227 & -3.73 & 0.000 & -430 & -0.366 & 1176 & Rejected $\mathrm{H}_{0}$ \\
\hline Ashotsk & 2012 & 2.967 & 0.003 & 376 & 0.284 & 1326 & Rejected $\mathrm{H}_{0}$ \\
\hline Ashtarak & 1090 & 2.64 & 0.022 & 122 & 0.301 & 406 & Rejected $\mathrm{H}_{0}$ \\
\hline Semyonovka & 2104 & -3.04 & 0.000 & -382 & -0.386 & 990 & Rejected $\mathrm{H}_{0}$ \\
\hline Sevan & 1917 & 3.086 & 0.002 & 369 & 0.301 & 1225 & Rejected $\mathrm{H}_{0}$ \\
\hline Chambarak & 1475 & -3.96 & 0.021 & -243 & -0.235 & 1035 & Rejected $\mathrm{H}_{0}$ \\
\hline Tashir & 1507 & 2.103 & 0.035 & 259 & 0.203 & 1275 & Rejected $\mathrm{H}_{0}$ \\
\hline Vorotan & 2387 & -3.59 & 0.021 & -228 & -0.241 & 946 & Rejected $\mathrm{H}_{0}$ \\
\hline
\end{tabular}


RA was inconsistent and finding any regularity proved to be challenging.

According to Kendall's tau-based test, four stations had significant annual increasing trends, and five stations had significant negative trends for the annual precipitation, whereas the annual trends for 27 stations were nonsignificant (Table 4). The most significant positive trend was observed in Sevan Lake ( $p=0.0020, \tau=-0.3012)$ station, and the most significant negative trends - in Aragats $h / m(p=0.000159$, $\tau=-0.36565)$ and Semyonovka $(p=0.000136, \tau=-0.38586)$ stations.

Considering the results from Table 4, a schematic map, as shown in Fig. 4, can be plotted, which demonstrates the geographical distribution of MK test results by grouping data obtained from each station. According to the map (Fig. 4), positive changes in precipitation were observed in the northwestern regions of RA, in the north of Sevan Lake (at Sevan station).

Negative changes were observed in the southwest of RA, as well as in high-altitude areas of Aragats mountain above $2000 \mathrm{~m}$ (at Aragats h/m and Amberd stations). Negative changes were observed in 6 stations from which four stations were located above $1800 \mathrm{~m}$ a.s.l.

\section{The trend analysis of floods series changes}

The data analysis of long-term extreme maximum instantaneous runoff of the rivers was performed using the above mantioned test. To demonstrate the characteristics of extreme maximum instantaneous runoff of the rivers, as it was already mentioned above, the data taken from the national meteorological services of Armenia (chosen 27 hydrometrical observational stations for 1960-2012 period) were located in the studied river basins and were distributed across the whole country (Fig. 1). To find out the presence of trends in extreme maximum instantaneous runoff of the rivers, nonparametric MK test and autocorrelation function were implemented. At the same time, graphs demonstrating the long-term temporal evolution of flood discharges and their drivers for rivers in RA were created (Fig. 5.1, 5.2)

According to MK test requirements, we had to get autocorrelation results (lag-1 serial correlation) for the data series before applying the data. The analysis was obtained by MK after eliminating the effect of significant lag-1 serial correlation from the time series. Thus, in this case, lag-1 was significant at the $5 \%$ level for all stations, therefore they were not pre-whitened before using in MK test (to the original values of the time series were applied for all stations).

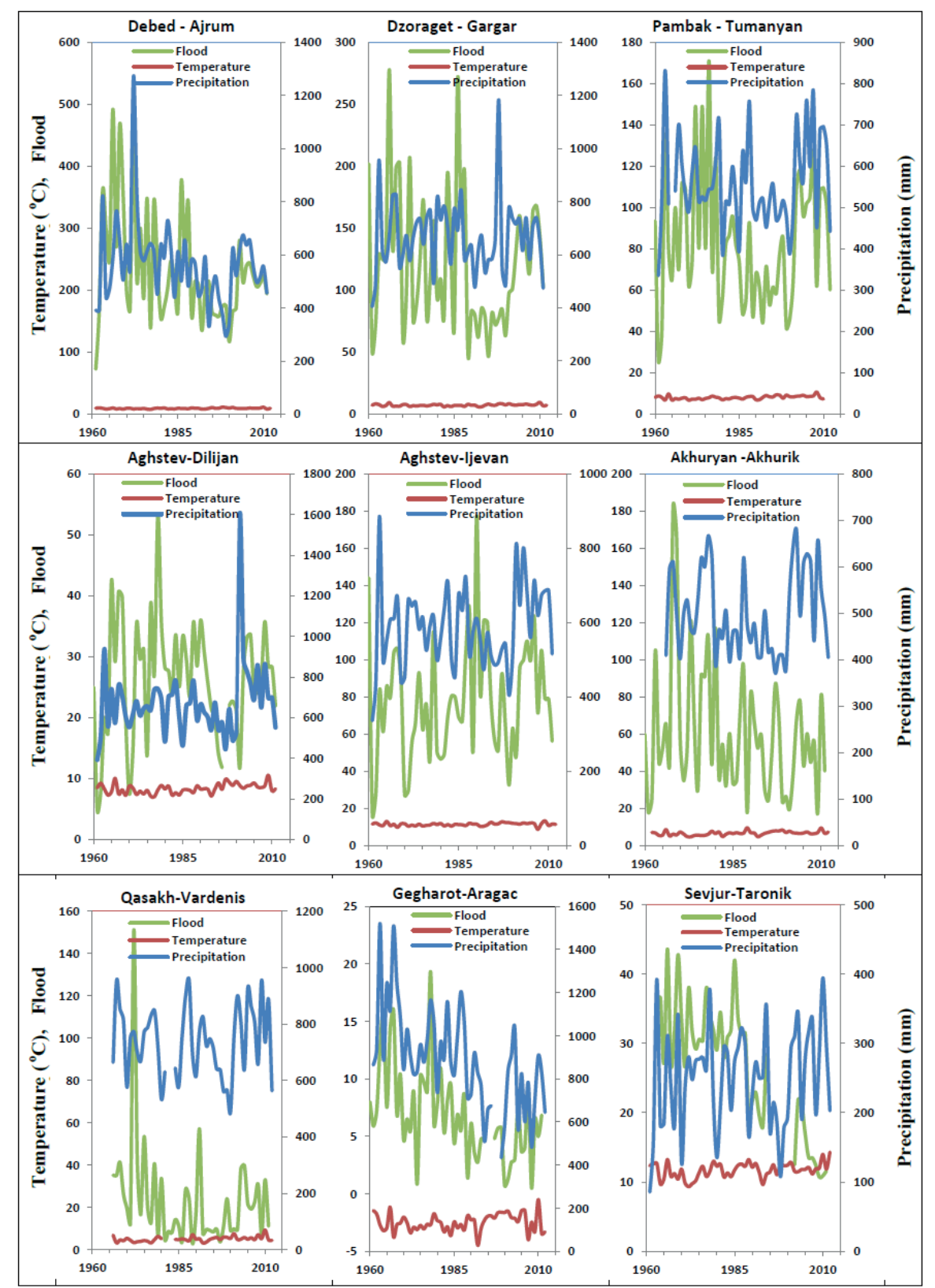

Fig. 5.1. Long-term temporal evolution of flood discharges and their drivers for some rivers in RA 


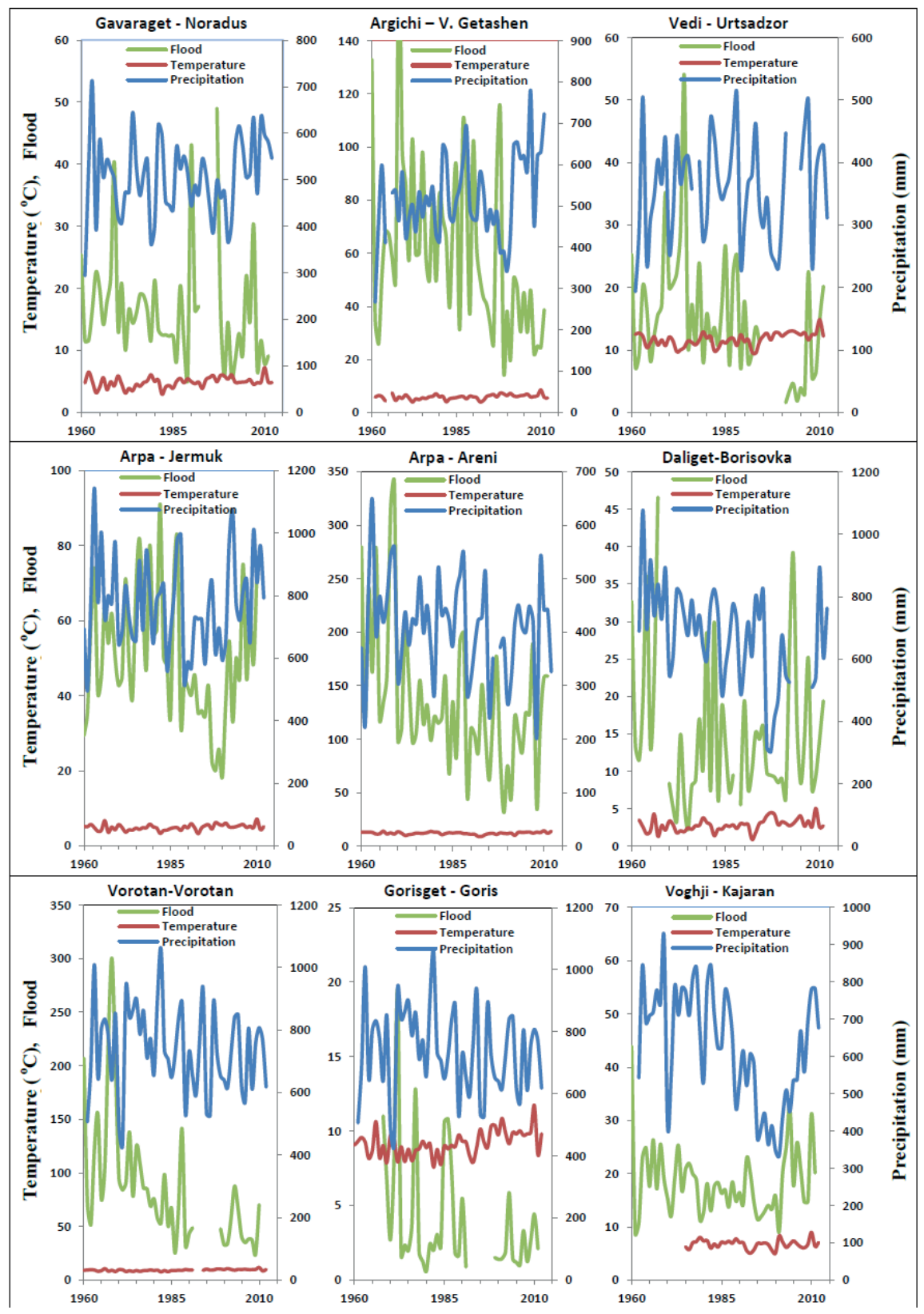

Fig. 5.2. Long-term temporal evolution of flood discharges and their drivers for some rivers in RA

Comparing average air temperature and atmospheric precipitation analyses with the extreme runoff of the rivers reveals more detailed information about the trend detection. Besides finding the increasing and decreasing trends, as well as no trend cases, the stability of the time series can be assessed as well. Thus, the stability during the studied period was investigated for some of the stations. Since the time series were found to be stable, the trend interpretation (the null hypothesis $(\mathrm{HO})$ ) was considered accepted.

According to the methodology requirement explained above, to find out if the time series have «No trend» or «Stable» characteristic, it was necessary for some stations to calculate COV, Since, for 11 stations $S \leq 0$ and CF $<90 \%$, COV was compulsory. COV calculation depends on the mean values and standard deviations (as given in Table 5). As the results demonstrate, only in one out of 11 stations «No trend» was detected, whereas for the other stations the extreme maximum instantaneous runoff was stable during the last five decades.

The null hypothesis $\left(\mathrm{H}_{0}\right)$ was accepted for 15 stations (this means that «No trend» or «Stable» were observed for these stations), while it was rejected for 12 remaining stations (there were trends) (Table 6). According to these results, during the studied period, extreme maximum instantaneous runoff increase was observed only in one river basin of RA (Dzknaget river basin, which is located from north of Sevan Lake). This is an indication of decline in extreme maximum instantaneous runoff occurrences in RA.

The spatial distribution of hydrometrical observational stations with decreasing, increasing, stable, and no trend results for the annual data series during the period 1960-2012 are presented in Fig. 5.1, 5.2, and 6. As shown, significant decreasing trends were detected in extreme maximum instantaneous runoff at ten of the observed stations. Moreover, the extreme maximum runoff was detected to have a «Probably decreasing» trend only in one river basin (in the northeastern edge of RA, for Debed river basin).

The strongest significant decreasing trend was found in VorotanVorotan ( $p=0, T=-0.64058)$, Karkachun-Gharibjanyan $(p=0, T=$ -0.51170 ) and Sevjur-Taronik ( $p=0, T=-0.57791$ ) stations.

Applying MK test results for every station, the schematic map can be plotted (Fig.6), where three major regions can be identified (with minor regions being «Increasing», «Probably decreasing» and «Not studied» areas). Those major regions are: «No trend» area, where the extreme maximum instantaneous runoff of the rivers did not change, «Stable» area, where they were considered stable during the studying period and «decreasing» area, where the extreme maximum instantaneous runoff of the rivers decreased. It can also be seen that there is a small northeastern edge marked «increasing» area (the word «area» represents the river basins). It can be visually 
Table 5. The Coefficient of Variation of extreme maximum instantaneous runoff of the rivers for eleven stations

\begin{tabular}{|c|c|c|c|c|c|}
\hline River Stations & Mean & Standard deviation & COV & CF \% & Trend \\
\hline Dzoraget - Gargar & 119.1 & 57.1 & 0.5 & 21.2 & Stable \\
\hline Aghstev - Dilijan & 26.3 & 9.6 & 0.4 & 12.9 & Stable \\
\hline Akhuryan - Akhurik & 61.5 & 36.5 & 0.6 & 79.6 & Stable \\
\hline Qasakh - Vardenis & 23.1 & 23.8 & 1.0 & 86.5 & No Trend \\
\hline Marmarik - Hanqavan & 16.7 & 6.1 & 0.4 & 69.6 & Stable \\
\hline Masrik - Tsovak & 9.8 & 4.0 & 0.4 & 8.6 & Stable \\
\hline Azat - Garni & 34.4 & 17.7 & 0.5 & 20.9 & Stable \\
\hline Arpa - Jermuk & 49.3 & 17.2 & 0.3 & 86.8 & Stable \\
\hline Daliget - Barisovka & 14.7 & 10.0 & 0.7 & 11.7 & Stable \\
\hline Voghji - Qajaran & 18.4 & 6.4 & 0.3 & 40.3 & Stable \\
\hline Meghriget - Meghri & 17.0 & 9.1 & 0.5 & 87.33 & Stable \\
\hline
\end{tabular}

Table 6. Results of MK test for extreme maximum instantaneous runoff of the rivers over 1960-2012 period

\begin{tabular}{|c|c|c|c|c|c|c|c|c|}
\hline River - Station & $Z$ & p-value & $\mathrm{S}$ & varS & tau & CF $\%$ & Trend & Test interpretation \\
\hline Debed - Ajrum & -1.89 & 0.058 & -234 & 15155.3 & -0.18 & 94 & Probably Decreasing & Rejected $\mathrm{H}_{0}$ \\
\hline Karkachun - Gharibjanyan & -5.34 & 0.000 & -678 & 16057.3 & -0.51 & 100 & Decreasing & Rejected $\mathrm{H}_{0}$ \\
\hline Gegharot - Aragats & -3.71 & 0.000 & -444 & 14290.7 & -0.36 & 100 & Decreasing & Rejected $\mathrm{H}_{0}$ \\
\hline Sevjur - Taronik & -5.38 & 0.000 & -497 & 8512.3 & -0.58 & 100 & Decreasing & Rejected $\mathrm{H}_{0}$ \\
\hline Dzknaget-Tsovagyugh & 2.17 & 0.030 & 260 & 14286.7 & 0.21 & 97 & Increasing & Rejected $\mathrm{H}_{0}$ \\
\hline Gavaraget - Noradus & -2.45 & 0.014 & -277 & 12651.0 & -0.25 & 99 & Decreasing & Rejected $\mathrm{H}_{0}$ \\
\hline Argichi - V. Getashen & -3.46 & 0.001 & -440 & 16059.3 & -0.33 & 100 & Decreasing & Rejected $\mathrm{H}_{0}$ \\
\hline Vedi - Urtsadzor & -2.58 & 0.010 & -273 & 11155.0 & -0.26 & 99 & Decreasing & Rejected $\mathrm{H}_{0}$ \\
\hline Arpa - Areni & -2.68 & 0.007 & -340 & 16052.7 & -0.26 & 99 & Decreasing & Rejected $\mathrm{H}_{0}$ \\
\hline Vorotan - Vorotan & -6.27 & 0.000 & -663 & 11155.0 & -0.64 & 100 & Decreasing & Rejected $\mathrm{H}_{0}$ \\
\hline Gorisget - Goris & -2.28 & 0.023 & -175 & 5845.0 & -0.26 & 98 & Decreasing & Rejected $\mathrm{H}_{0}$ \\
\hline Voghji - Kapan & -2.33 & 0.020 & -194 & 6832.7 & -0.26 & 98 & Decreasing & Rejected $\mathrm{H}_{0}$ \\
\hline
\end{tabular}

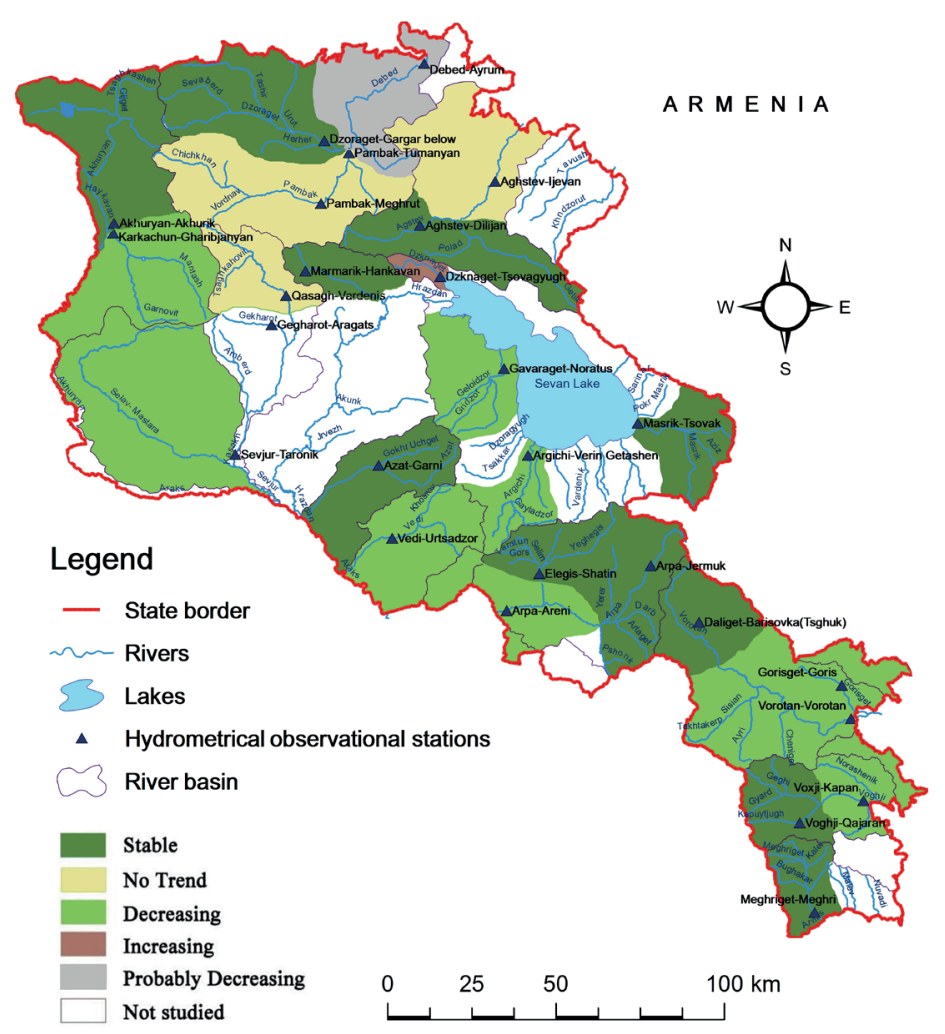

Fig.6. Mann-Kendall test results for extreme maximum instantaneous runoff of the rivers over the period 1960-2012 
seen from Fig. 6 that the «Decreasing» area is twice as large as «No trend» and «Stable» areas. «No trend» was detected in Pambak river basin, the middle course of Aghstev river, and the upper course of Qasakh river basins. The extreme maximum instantaneous runoff «Decreasing» areas were identified in the following regions: the west of Ararat valley and the southern, south-western and northwestern slopes of Aragats mountain (lower course of Qasakh river, Amberd, Gegharot, Mastara river basins), the lower course of Arpa and Vedi river basins, from Sevan Lake basin Gavaraget and Argichi river basins, in the south of the country, mainly in the lower course of Voghji and in the middle course of Vorotan river basins.

«Stable» extreme maximum runoff was detected especially in the upper course of of Akhuryan, Dzoraget river (in the north-west of RA), the upper courses of Aghstev, Arpa, Eghegis, Vrotan and Voghji river basins (from north to south), from Sevan Lake basin only Masrik river basin, in the south edge was Meghri river basin and in the central part of RA was Azat river basin.

In fact, the «decreasing» extreme maximum instantaneous runoff (observed last five decades over the most territory of Armenia) was mainly influenced by global climate change, which had its effects almost everywhere. As it was shown above, the average temperature increased, and the precipitation decreased during the same period, which had a significant influence on the formation of the extreme maximum instantaneous runoff of the rivers.

Similar studies in Europe demonstrate that the climate change both increased and decreased the flooding risks in different river basins of the continent (Blösch G. et al. 2019). Analyzing the longterm temporal evolution of flood discharges and their drivers (temperature and precipitation) for seven hotspots in four regions (Northern Iberia, Central Balkans, Southern Finland and Western Russia) in different parts of Europa (Blösch G. et al. 2019), it was found, that flood and temperature changes were similarl to what was discussed above for RA. Moreover, the discussed three parameter (including precipitation) changes had a similar pattern as in RA only in Northern Iberia and Central Balkans. Considering the last statement, it is difficult to identify any flood formation factor, which would be the same for all regions, except climate change. Therefore, it can be argued that climate change is the primary factor of these changes.

According to our calculations, $60-70 \%$ of the average annual river runoff in RA passed during the overflow season (spring), and the rivers became low-water in summer and winter (Vardanyan 2006). The maximum instantaneous river runoffs were on average 25-30 times higher than the annual norm (Table 1), and in some cases, they were more than a hundred times (for Qasakh - Vardenis it was 120 times more) in the case of dominance of underground alimentation of the rivers.

For all studied rivers, the extreme maximum instantaneous runoff during the 1960-2012 period was calculated and compared with average values over the last years (expressed in $\mathrm{m} 3$ and percent) using trend equations (Table 7).

Table 7. The change characteristics of extreme maximum instantaneous runoff of the relatively major rivers of RA

\begin{tabular}{|c|c|c|c|c|c|c|}
\hline \multirow{2}{*}{$\mathrm{N}$} & \multirow{2}{*}{ River - Hydrometric station } & \multirow{2}{*}{ Trendline equation } & \multirow{2}{*}{$\begin{array}{l}\text { The correlation } \\
\text { coefficient (R) }\end{array}$} & \multirow{2}{*}{$\begin{array}{l}\text { Extreme maximum } \\
\text { runoff norm, } \mathrm{m}^{3} / \mathrm{s}\end{array}$} & \multicolumn{2}{|c|}{ Runoff change } \\
\hline & & & & & $\mathrm{m}^{3} / \mathrm{s}$ & $\%$ \\
\hline 1 & Debed - Ajrum & $y=-2.135 x+4474.7$ & -0.35 & 234.1 & -54.8 & -23.4 \\
\hline 2 & Dzoraget - Gargar & $y=-0.560 x+1233.3$ & -0.16 & 121.3 & -15.5 & -12.8 \\
\hline 3 & Pambak - Meghrut & $y=0.033 x-7.6$ & 0.02 & 57.6 & 0.65 & 1.1 \\
\hline 4 & Pambak - Tumanyan & $y=-0.045 x+172.0$ & -0.02 & 82.7 & -0.95 & -1.1 \\
\hline 5 & Aghstev - Dilijan & $y=0.019 x-11.7$ & 0.03 & 26.3 & 0.56 & 2.1 \\
\hline 6 & Aghstev - ljevan & $y=0.364 x-644.6$ & 0.21 & 78.2 & 8.6 & 11.0 \\
\hline 7 & Akhuryan - Akhurik & $y=-0.585 x+1222.5$ & -0.25 & 60.2 & -15.8 & -26.2 \\
\hline 8 & Karkachun - Garibjanyan & $y=-0.383 x+769.5$ & -0.50 & 9.03 & -5.1 & -56.5 \\
\hline 9 & Qasakh - Vardenis & $y=-0.484 x+984.9$ & -0.27 & 23.1 & -11.1 & -48.1 \\
\hline 10 & Gegharot - Apagats & $y=-0.134 x+272.1$ & -0.52 & 6.9 & -3.4 & -49.6 \\
\hline 11 & Sevjur - Taronik & $y=-0.523 x+1065.1$ & -0.83 & 27.1 & -14.1 & -52.0 \\
\hline 12 & Marmarik - Hankavan & $y=-0.068 x+150.9$ & -0.17 & 16.7 & -1.9 & -11.4 \\
\hline 13 & Dzknaget - Tsovagyugh & $y=0.150 x-284.6$ & 0.37 & 13.7 & 3.7 & 27.0 \\
\hline 14 & Gavaraget - Noradus & $y=-0.101 x+216.4$ & -0.17 & 16.5 & -2.8 & -17.0 \\
\hline 15 & Argichi - Verin Getashen & $y=-0.927 x+1900.8$ & -0.44 & 60.5 & -23.5 & -38.8 \\
\hline 16 & Masrik-Tsovak & $y=-0.027 x+6 . .0$ & -0.09 & 9.8 & -0.7 & -7.1 \\
\hline 17 & Azat - Garni & $y=-0.030 x+94.2$ & -0.03 & 34,4 & -0.8 & -2.3 \\
\hline 18 & Vedi-Urtsadzor & $y=-0.246 x+503.4$ & -0.39 & 15.0 & -7.0 & -46.7 \\
\hline 19 & Arpa - Jermuk & $y=-0.227 x+501.3$ & -0.20 & 50.2 & -6.3 & -12.6 \\
\hline 20 & Arpa - Areni & $y=-1.983 x+4072.4$ & -0.46 & 135.2 & -51.6 & -38.2 \\
\hline 21 & Elegis - Shatin & $y=-0.425 x+905.3$ & -0.18 & 61.7 & -11.2 & -18.2 \\
\hline 22 & Daliget - Borisovka & $y=-0.086 x+185.4$ & -0.13 & 14.7 & -2.2 & -15.0 \\
\hline 23 & Vorotan - Vorotan & $y=-2.240 x+4529.0$ & -0.59 & 86.6 & -63.3 & -73.1 \\
\hline 24 & Gorisget - Goris & $y=-0.117 x+237.5$ & -0.39 & 4.1 & -2.46 & -60.0 \\
\hline 25 & Voghji - Kajaran & $y=-0.033 x+84.2$ & -0.08 & 18.4 & -1.0 & -5.4 \\
\hline 26 & Voghji - Kapan & $y=-0.895 x+1836.1$ & -0.50 & 58.4 & -23.5 & -40.2 \\
\hline 27 & Meghriget - Meghri & $y=-0.122 x+258.9$ & -0.20 & 17.1 & -3.2 & -18.7 \\
\hline
\end{tabular}


As it can be seen from Table 7, only in four stations out of the studied 27 stations, the extreme maximum instantaneous runoff had a positive tendency (it increased), while it decreased for the remaining stations. A relatively high value (27 \%) was observed in Dzknaget, while it was very insignificant (1-2\%) in two other stations. The reasons for the «increasing» tendency is not explained yet, especially, in Dzknaget river basin, where temperature increas was observed. In contrast to other studied river basins, Dzknaget river basin is considered the smallest one (85 km2), hence local factors may skew the results. Relatively high values of extreme maximum instantaneous runoff (more than 50\%) were obtained for four rivers (Sevjur-52 $\%$, Karkachun-56.5\%, Gorisget-60\%, and Vorotan-73.1\%). On the other hand, the extreme maximum instantaneous runoffs decreased in 9 river basins (20-50\%). For the other river basins, the changes were negligible, and in some cases, the changes could be 1-2\% (Table 7).

In our opinion, the downward trend in the extreme maximum instantaneous runoff was mainly due to air temperature increase and precipitation decrease at these areas, which were almost certainly due to global climate change. Still, there may be some local factors that may require further attention. Comparing the observed extreme maximum instantaneous runoff of the rivers with long-term air temperature changes in the same river basins during the same period, it was clear that the temperature increased for almost all river basins (Fig. 5.12). The average annual air temperature compared with 1961-1990 baseline period (adopted by IPCC) increased by $1.03^{\circ} \mathrm{C}$ (Armenia's Third National Communication on Climate Change 2015; Galstyan et al. 2017). As a result, the snow can not accumulate in many river basins as it melts due to increasing air temperature in winter (Vardanian 2017). Starting early spring, it gradually melts, and the possibility of an extreme maximum instantaneous runoff in late spring decreases or completely disappears, therefore, the risk of the flood occurrence disappears as well.It can be concluded that the extreme maximum air temperatures contributed to the runoff reduction of rivers, resulting in decline in the risk of possible flood occurance.

\section{CONCLUSIONS}

This paper provided the review of characteristics of extreme maximum runoff of the rivers RA in the context of global climate change. The temporal and spatial distribution of the extreme maximum instantaneous runoff, as well as air temperature and precipitation database was evaluated and compared. There was a clear reduction in extreme maximum instantaneous runoff potential in almost all the investigated riversas a consequence of increase of the average annual air temperature and decrease in precipitation during the same period. Based on the results presented, it can be claimed that the degree of flooding risk in the river basins drastically reduced due to the increase in average annual air temperatures, which prevents the snow accumulation in many river basins, since it melts due to increasing air temperature in winter. From early spring, it gradually melts, and the possibility of an extreme maximum instantaneous runoff in late spring decreases or completely disappeares, reducing the risk of the flood occurrence.

In conclusion, it can be claimed that because of the global climate change, almost all the river basins of RA have a tendency to reduce the risk of floods.

\section{REFERENCES}

Anderson R.L. (1942). Distribution of the Serial Correlation Coefficients', Annals of Meth. Statistics 13(1), 1-13.

Anthony J., Vardanian T. and Hakopian Ch. (2009). Threats to global water security, Springer Science \& Business Media, Dordrecht, Netherlands, 400, DOI: 10.1007/978-90-481-2344-5.

Armenia's Third National Communication on Climate Change (2015). Edited by Vermishev M. / «Lusabats» Publishing House, Yerevan, 165.

Atlas of Natural Hazards and Risk in Georgia (2012). Editor: Van Western/, Publisher: CENN Caucasus Environmental NGO Network.

Atlas of the natural conditions of the natural resources of the Republic of Armenia, Hydrology (1990). Ed. A. B. Bagdasaryan, Yerevan,

Publishing house of Inst. Geol. Sciences Academy of Sciences, 112 (in Russian).

Aziz J.J., Ling M., Rifai H.S., Newell C.J. and Gonzales J.R. (2003). «MAROS: A Decision Support System for Optimizing Monitoring Plans.»

Ground Water 41(3), 355-367.

The Hydrography of Armenian SSR (1981). Yerevan, Publishing House of the Academy of Sciences Arm. SSR, 178 (in Armenian).

Blösch G., Hall J., Viglione A., et al. (2019). Changing climate both increases and decreases European river floods, Nature. Nature Publishing

Group, United Kingdom, 16, DOI: 10.1038/s41586-019-1495-6.

Climate Bulletin of the Republic of Armenia (2011). ArmStateHydromet, Yerevan, 150 (in Armenian)

Galstyan H.S., Vardanyan T.G. (2017). The dynamics of average annual air temperature changes in the Republic of Armenia. Proceedings

of YSU, Geology and Geography, 51(1), 68-71, Available at: http://test.journals.sci.am/index.php/ysu-proceedings-gelogy/article/view/4149.

Geology of the Armenian USR (1974). vol. VIII-Hydrogeology. Yerevan: Publishing House Academy of Sciences Arm. USR, $1974,392$.

Jones P., Wigley T. and Wright P. (1986). Global Temperature Variations between 1861 and 1984, Nature, 322, 430-434.

Kendall M.G. (1975). Rank Correlation Methods: 4th edition, Griffin, London, UK, 202.

Khaled H. Hamed, Ramachandra A. Rao. (1998). A modified Mann-Kendall trend test for autocorrelated data Journal of Hydrology, 204(1-

4), 30 January, 182-196.

Mann H.B. (1945). Nonparametric tests against trend. Econometrica 13, 245-259.

Nersisyan A.G. (1964). Climate of Armenia, Armstatepub., Yerevan, 303 (in Armenian)

Physical geography of the Armenian USR (1971). Yerevan: Publishing house of the Academy of Sciences of the Armenian USR, 471 (in Armenian).

Salas J.D., Delleur J.W., Yevjevich V. and Lane W.L. (1980). Applied Modeling of Hydrologic Time Series, Water Resources Publications, Littleton, CO.

Scientific Applied Directory on the USSR Climate. (1989). Issue 16, part 3. Armenian SSR. Leningrad, 365 (in Russian).

Solomon S. D. Qin, Manning M., Chen Z., Marquis M., Averyt K. B., Tignor M. and Miller H. L. (2007). IPCC: Climate Change. The Physical Science Basis. Contribution of Working Group I to the Fourth Assessment Report of the Intergovernmental Panel on Climate Change Cambridge University Press, Cambridge, United Kingdom and New York, NY, USA, 996.

Stephens G.L., Ellis T.D. (2008). Controls of global-mean precipitation increases in global warming GCM experiments. J Clim 21:61416155. 
Trahel Vardanian (2007). Will the Present-Day Scientific Approaches Enable to Forecast Natural Disasters? In: Scientific Support for the Decision Making in the Security Sector. Edited by Ognyan Kounchev, Rene Willems, Velizar Shalamanov and Tsvetomir Tsachev. NATO Science for Peace and Security Series - D: Information and Communication Security, Amsterdam-Berlin-Oxford-Tokyo-Washington, DC: IOS Press, 12, 267-273.

Transboundary Floods (2005). Reducing Risks and Enhancing Security through Improved Flood Management Planning. Proceedings of the NATO Advanced Research Workshop, Oradea (Baile Felix), Romania, 492. Available at: https://www.amazon.co.uk/Transboundary-FloodsReducing-Through-Management/dp/1402049013.

Vardanyan T.G. (2005). The Application of Mathematical Methods for Flood Forecasting. In: Transboundary Floods: Reducing Risks and Enhancing Security through Improved Flood Management Planning. Proceedings of the NATO Advanced Research Workshop, Oradea (Baile Felix), Romania, 250-257.

Vardanyan T.G. (2006). River Runoff in Armenia and the Assessment of its Change Under the Global Warming of Climate. Yerevan: Yerevan University Press, (ISBN 5-8084-0753-2), 178 (in Russian).

Vardanian T.G. (2007). Characteristics of changes in annual discharge of Armenia's rivers. Geography and natural resources (Scientific journal of the Siberian Branch of the Russian Academy of Sciences) № 2, 169-177, Available at: http://www.izdatgeo.ru/journal. php?action=output_more\&id=3\&lang_num=1\&year=2007\&issue=2\&nodoi=1\&page=169 (in Russian)

Vardanian T. (2008). The Issues of Transboundary Rivers in South Caucasus at the End of the 20th and Beginning of the 21 st Centuries. In: Lagutov V. (eds) Rescue of Sturgeon Species in the Ural River Basin. NATO Science for Peace and Security Series C: Environmental Security. Springer, 53-58, Dordrecht, DOI: 10.1007/978-1-4020-8924-4_4.

Vardanian T.G. (2009). Water Disasters in the Territory of Armenia. In: Jones J.A.A., Vardanian T.G., Hakopian C. (eds) Threats to Global Water Security. NATO Science for Peace and Security Series C: Environmental Security. Springer, 215-224, Dordrecht, DOI: 10.1007/978-90-481-23445_24.

Vardanian T.G. (2017). Specific features of extreme maximum river runoffs in the context of global climate change (Case Study of the Rivers of the Republic of Armenia). Scientific notes of the Russian State Hydrometeorological University, 46, 43-50. Available at: http://www. rshu.ru/university/notes/rggmu_uchenye_zapiski_full_46.pdf.

Von Storch H., Navarra A. (1995). Analysis of Climate Variability - Applications of Statistical Techniques, Springer- Verlag, New York, 342 , DOI: 10.1007/978-3-662-03744-7.

Yue S., Wang C. (2004). The Mann-Kendall Test Modified by Effective Sample Size to Detect Trend in Serially Correlated Hydrological Series. Water Resources Management 18, 201-218.

Zaqaryan N.B., Vardanyan T.G., Melqonyan H.A. (2018). The assessment of some bioclimatic indices affecting on human health in the Yerevan city. Proceedings of YSU, Geology and Geography, 52(2), 102-108. (in Armenian with English summary). Available at: http://test. journals.sci.am/index.php/ysu-proceedings-gelogy/article/view/4184. 